\title{
Metaplastic carcinoma breast (IDC and chondrosarcoma): a rare entity
}

\author{
Deepesh Kalra*, Bhanu Kaushik, Shalu Gupta, Pradeep Tanwar, Sami Anwar Khan
}

Department of General Surgery, SMS Medical College and Hospital, Jaipur, Rajasthan, India.

Received: 01 May 2018

Accepted: 29 May 2018

\section{*Correspondence:}

Dr. Deepesh Kalra,

E-mail:kd89.doc@gmail.com

Copyright: (C) the author(s), publisher and licensee Medip Academy. This is an open-access article distributed under the terms of the Creative Commons Attribution Non-Commercial License, which permits unrestricted non-commercial use, distribution, and reproduction in any medium, provided the original work is properly cited.

\begin{abstract}
Metaplastic breast carcinoma is very rare neoplasm. Authors report a case of metaplastic breast carcinoma containing characteristic features of infiltrating ductal carcinoma and chondrosarcoma. A 62-year-old female presented with complaint of a lump in the right breast for the last 2 years. FNAC was suggestive of mucinous tumour. Tru-cut biopsy had been performed outside the institution, which was suggestive of a Ductal carcinoma with mucinous component. Modified radical mastectomy of the right breast was performed and histopathology was suggestive of infiltrating ductal carcinoma and chondrosarcoma of the right breast. All resected lymph nodes were free of metastasis. Immunohistochemistry was suggestive of a metaplastic carcinoma with components of ductal carcinoma and chondrosarcoma with moderately positive ER, negative PR, positive Pancytokeratin in ductal carcinoma component, positive S-100 and KI-67.
\end{abstract}

Keywords: Breast carcinoma, Chondrosarcoma, Metaplastic carcinoma

\section{INTRODUCTION}

Metaplastic carcinoma with chondrosarcoma of the breast is exceedingly rare. Most benign and malignant tumors of the breast arise from the glandular epithelium. However, in some cases, the glandular epithelium differentiates into nonglandular mesenchymal tissue, a process called metaplasia. $^{1}$

Metaplastic changes, including squamous cell, spindle cell, and heterologous mesenchymal growth, occur in fewer than $5 \%$ of breast carcinomas. Sarcomas of the breast are relatively rare, accounting for less than $1 \%$ of all primary malignant tumors of the female breast. $^{2}$ Carcinosarcomas, a subgroup of metaplastic carcinomas, are the rarest primary malignancies of the breast (found in $<0.1 \%$ of cases). ${ }^{3}$ Metaplastic carcinomas are usually seen in women over 50 years of age. Here, authors present a case of metaplastic carcinoma with chondrosarcoma of the right breast. Authors report this case because of its rarity.

\section{CASE REPORT}

A 62-year-old female presented with complaint of a lump in the right breast for the last 2 years. On examination, there was a painless, hard lump of $10 * 10 \mathrm{~cm}$ in the right breast lower, outer quadrant nipple was retracted, few dry skin ulcers were present over lump. No axillary lymph node was palpable. The opposite breast and the axilla were normal. Hematological investigations were within normal limits, chest X-ray, ECG, USG abdomen heart and lung functions were normal. FNAC and Tru-cut biopsy of the right breast lesion delivered the diagnosis of a ductal carcinoma with mucinous component of the right breast. Modified radical mastectomy of the right breast with axillary dissection was done. The postoperative period was uneventful.

On gross examination, tumor measured $9.5 * 8 * 10 \mathrm{~cm}$ it showed areas of necrosis and haemorrhage involving skin ulcerated and $0.1 \mathrm{~cm}$ from base (Figure 1 and 2). Histopathology was suggestive of a metaplastic 
carcinoma (chondrosarcoma and infiltrating ductal carcinoma NOS). Axillary lymph nodes were free of tumor. Immunohistochemistry was suggestive of an infiltrating duct carcinoma of the right breast with a chondrosarcomatous component. Estrogen receptor (ER) was moderately positive, progesterone receptor (PR) was not detectable, and c-erbB2 showed 0 score. Pan cytokeratin was positive in ducatal carcinoma component. S-100 and KI-67 were positive in the metaplastic area, which confirms the presence of metaplastic carcinoma with chondrosarcoma with infiltrating duct carcinoma. further treatment plan consisting of radio-chemotherapy.

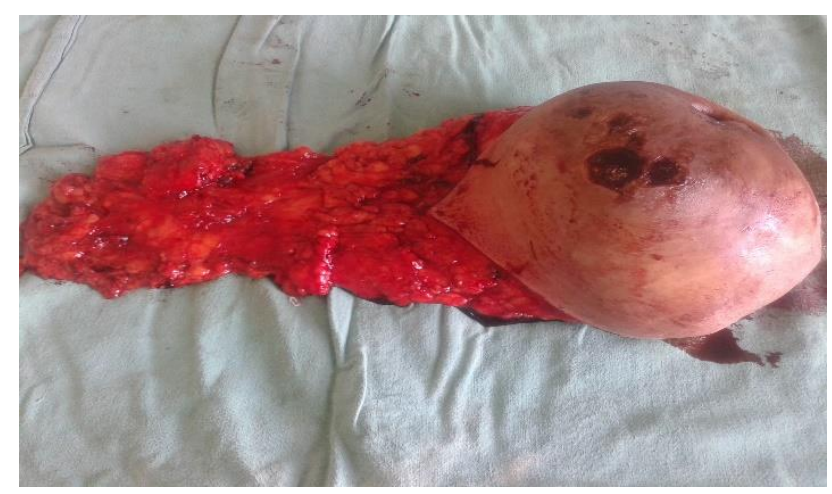

Figure 1: Gross photograph of the specimen.

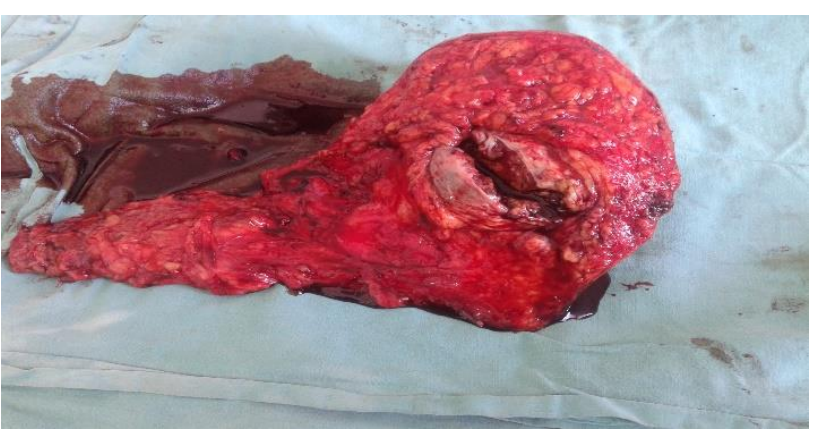

Figure 2: Cut specimen.

\section{DISCUSSION}

The term metaplastic carcinoma was first introduced by Huvos et al. Metaplasia into a non-glandular growth pattern and are difficult to accurately diagnose and classify because of their rarity and varied histological pattern. Tumors showing both carcinomatous and sarcomatous features are very uncommon and occur in various anatomical sites. ${ }^{4}$ Metaplastic carcinomas of the breast are rare and interesting, yet confusing neoplasms. It has been reported that these tumors are more likely to occur in women over 50 years of age. ${ }^{5,6}$ The patients usually describe a rapid growth with a short period of diagnosis. The tumors tend to have a circumscribed contour radiologically. A preoperative clinical and cytological diagnosis, though possible in a few cases, is usually not reached both due to marked similarity in clinical behavior and low index of suspicion. Classic sarcomatoid carcinoma is a tumor with both epithelial and mesenchymal components, hence the term biphasic sarcomatoid carcinoma. There are four variants of metaplastic carcinoma: matrix producing carcinoma, carcinosarcoma, squamous cell carcinoma and spindle cell carcinoma. Four carcinomas showing extensive metaplastic changes, including spindle cells, squamous cells and heterologous mesenchymal elements, are recognized in the breast. ${ }^{7}$ In most of these cases, the infiltrating duct carcinoma is very small or focal or difficult to observe with routine HE stains or histopathological sections. Confirmation of epithelial (carcinomatous) component by immunohistochemical study is necessary in such cases to rule out pure primary mammary sarcomas. Metaplastic elements of pleomorphic spindle cells like fibrosarcoma, high-grade sarcomas, are rarely seen. However, chondrosarcoma, osteosarcoma and leiomyosarcoma components are extremely rare. In present case, the malignant chondrosarcomatous element was predominant; the infiltrating duct carcinoma was very focal and difficult to demonstrate in multiple histopathological sections. Therefore, authors confirmed it by immunohistochemical study, which showed strong positivity for S-100 protein in chondromatous areas and focal positivity for cytokeratins and epithelial membrane antigen, while the tumor was negative for ER, PR and c-erbB2.

The prognosis of patients with metaplastic breast carcinoma depends on the stage of disease, similar to that seen in invasive carcinomas of the breast. ${ }^{8,9}$

Tumor size is another prognostic factor. Patients with a tumor size not larger than $5 \mathrm{~cm}$ have a better survival rate. Findings reported by Oberman, Kaufman et al., and Chao et al. suggest that the size of the neoplasm at the time of initial treatment best correlated with the prognosis. ${ }^{9}$ In present case, tumor size is larger than 5 $\mathrm{cm}$, which is an unfavorable prognosis.

The incidence of axillary lymph node metastasis is low in metaplastic carcinomas. Like invasive carcinomas of the breast, axillary lymph node metastasis in patients with metaplastic carcinoma correlates with poor prognosis. ${ }^{9,10}$ In present case, axillary lymph node metastasis was positive. The incidence of metastatic malignancy is very rare. One of these cases with pulmonary metastasis is reported by Beltaos et al.

Metaplastic carcinoma rarely exhibits nuclear immunoreactivity for ER and PR. Expression of markers 34BE12, p53, retinoblastoma protein, HER/2neu, epidermal growth factor receptor, and cyclin D1 does not correlate with clinicopathologic features such as patient age, tumor size, tumor type, and relative proportion of metaplastic elements. ${ }^{10}$

Surgery remains the mainstay of treatment for most sarcomatoid tumors. ${ }^{11}$ Multimodality treatment may decrease local and systemic recurrence rates of somatic 
sarcomas, but results are inconclusive in patients with breast sarcomas. ${ }^{11}$ Surgical and adjuvant treatment should follow the guidelines for the other most common breast cancers even if the need for chemotherapy is unknown due to the absence of large series of randomized or observational data.

Authors report on a case of metaplastic carcinoma with predominant chondrosarcoma with axillary metastasis. The patient is on regular follow-up on outpatient basis.

There has been no evidence of local recurrence of the disease or distant metastasis. Regular follow-up of the patient is important for at least 5 years because recurrence rates are high. The overall 5-year disease-free survival rate is $43 \%$ in metaplastic breast carcinoma. ${ }^{12}$

Funding: No funding sources

Conflict of interest: None declared

Ethical approval: Not required

\section{REFERENCES}

1. Brenner RJ, Turner RR, Schiller V, Arndt RD, Giuliano A. Metaplastic carcinoma of the breast: report of three cases. Cancer. 1998;82:1082-7.

2. Beltaos E, Banerjee TK. Chondrosarcoma of the breast: Report of 2 cases. Am J Clin Pathol. 1979;71:345-9.

3. Feder JM, de Paredes ES, Hogge P, Wilken JJ. Unusual breast lesions: radiologic-pathologic correlation. Radiographics. 1999;19(suppl):S11-26.

4. Kurian KM, Al-Nafussi A. Sarcomatoid/ metaplastic carcinoma of the breast: a clinicopathological study of 12 cases. Histopathol. 2002;40:58-64.
5. Oberman HA. Metaplastic carcinoma of breast: A clinicopathological study of 29 patients. Am J Surg Pathol. 1987;11:918-29.

6. Kaufman MW, Marti JR, Gallager HS, et al. Carcinoma of the breast with pseudosarcomatous metaplasia.Cancer. 1984;53:1908-17.

7. Schitt SJ, Millis RR, Hanby AM, Oberman HA. The breast. Chapter 9 in Sternberg's Diagnostic Surgical Pathology. vol 1. Lippincott: W\&W; 2004:365-366.

8. Clark GM. Prognostic and predictive factors. In: Harris JR, Lippman ME, Morrow M, Hellman S, editors. 'Disease of the Breast'. Philadelphia: Lippincott-Raven publishers; 1996:461-485.

9. Chao TC, Wang CS, Chen SC, Chen MF. Metaplastic carcinomas of the breast. J Surg Oncol. 1999;71:220-5.

10. Chhieng C, Cranor M, Lesser ME, Rosen PP. Metaplastic carcinoma of the breast with osteocartilaginous heterologous elements. Am J Surg Pathol. 1998;22:188-94.

11. Callery CD, Rosen PP, Kinne DW. Sarcoma of the breast. A study of 32 patients with reappraisal of classification and therapy. Ann Surg. 1985;201:52732.

12. Pitts WC, Rojas VA, Gaffey MG, Rouse RV, Esteban J, Frierson HF, et al. Carcinoma with metaplasia and sarcomas of the breast. Am J Clin Pathol. 1991;95:623-32.

Cite this article as: Kalra D, Kaushik B, Gupta S, Tanwar P, Khan SA. Metaplastic carcinoma breast (IDC and chondrosarcoma): a rare entity. Int Surg J 2018;5:2646-8. 